\title{
Assessment of Modern Architecture in the Living City of UAE: Incorporating Sustainable Design into Covered Bazaar Buildings
}

\author{
Mohamed El Amrousi ${ }^{l}$, and Feda Isam AbdulHafiz ${ }^{2 *}$ \\ ${ }^{1}$ Department of Architecture, Abu Dhabi University, Abu Dhabi 59911, UAE
}

\begin{abstract}
In the UAE modern architecture is now considered part of early attempt of sustainable design and heritage of the living city that reflects good design practices, especially after the establishment of the Urban Planning Council and Estidama Guidelines. Madinat Zayed Gold Souk/bazaar still attracts many visitors because it represents a space of specialization, tt is also a representative of 'modernism' of 1970s Parallel examples such as the Central Market/Gold bazaar in Sharjah also manifest architectural attempts to create architecture within cultural and environmental contexts. Traditional wind towers known as Barjeel, vaults, domes and arcades borrowed from the broader spectrum of Islamic arts, recreated in concrete act as architectural containers of heritage and spaces of socio-cultural interaction accessible to all social groups. The aim of this research is to examine modern Arab ornament and its application on buildings in the downtowns of Abu Dhabi and Sharjah. This research examines the environmental properties of the gold bazaars in Abu Dhabi and Sharjah using Formit architectural modelling software. This study outlines the importance of forms of representation of form and identity in rapidly developing Arab cities and proposes a number of solutions/designs to improve the facades, and to enhance the comfort in the building then offers scenarios to make these buildings more sustainable.
\end{abstract}

\section{Introduction}

The rapid growing urban sprawl of cities in the UAE, triggers the problem of preserving cultural identity of the living city. In Abu Dhabi very little urban heritage remains, and the city grew in the 1970's therefore it was conceived as a modern city. The Desert environment and Bedouin culture is felt on the human level however, within an architectural context principles of modernism and the extensive use of concrete, steel and glass have clear reference to the city of Manhattan with its ability to host a highly urbanized settlement [1]. As Pascal Menoret outlines, the buildings of Abu Dhabi during the 1970's manifest architectural attempts to create a fusion between modernism and vernacularism [2]. The city of Sharjah on the other hand developed independently from its neighbour Dubai by juxtaposing its urban identity that are founded on re-interpretations of Islamic architecture. Modernity and tradition are exhibited through the employment of vaults, domes and tilework that manifest its conservative cultural aura and reinforced concrete as a construction material. The Central Souk in Sharjah, its form, decor and surrounding landscape best exemplify the role of architecture in shaping the urban identity of the city (Figure 1).

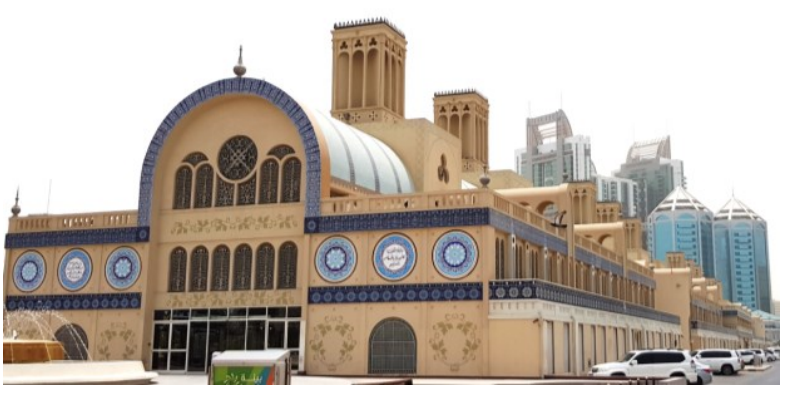

Fig. 1. Sharjah Central Souk/Gold Bazaar

The relation between the traditional bazaar, the congregational mosque and open space has always constituted a central node and place of gathering in Arab cities. The Central Souk in Sharjah with its vaulted architecture, projecting wind-towers and stucco screen windows is an icon of the city reflecting on the role of architecture in weaving forms and fragments from a wide spectrum of Islamic arts to highlight the amalgamation of multi-ethnic communities within the city, and the shift from nomadic to urban centres. Here the balance between modernity and tradition and the search for an identity represented a challenge because of rapid city growth which overshadows the remaining

\footnotetext{
* Corresponding author: feda.isam@adu.ac.ae
} 
historic district also known as the heart of Sharjah, which is still intact around Al-Hisn Fort.

\section{Research Objectives and Methodology}

This paper examines Arab ornament and its applications in the Gold Bazaars of Abu Dhabi and Sharjah. The intention of this paper is to highlight the importance of Arab/Islamic forms and modern architecture form and city identity in relation to sustainability and urban context. This research also outlines the importance of forms of representation of form and identity in the bazaars in rapidly modernizing Arab cities and how they relate to their urban context and the morphology of the living city. Two case studies are examined; the Sharjah Gold Souk/bazaar and Madinat Zayed Gold Souk highlight the larger theoretical framework discussing the notion of modern heritage and environmental design. In addition to the literature review a photographic survey and a graphical reconstruction of the two bazaars is essential analyzing the contextual integration of designs based on modernist ideals and the 'International Style' in modern Arab cities - Sharjah and Abu Dhabi. Finally, this study proposes a number of solutions/designs to improve the facades, and to enhance the comfort in the building.

\section{Literary Review}

Curved roofs as a structural system to cover large spaces of gathering existed since Roman times as exemplified by remains of the Baths of Caracalla in Rome. In the Muslim World the structural abilities of vaults and domes to host large areas for social gathering beneath them have become part of the iconic traits of Islamic architecture. In hot arid regions, the bazaars of Isfahan and Istanbul with their various vaulted structures and domed structures have shown that buildings with curved roofs maintained lower temperatures during the hot summer months and reflect more radiation than flat roofs [3]. Many architects attempted to revive curved roof architecture employing domes, vaults and arcades one of the most famous is Hasan Fathy who believed that the intensity of solar radiation is spread over a larger area and heat transmission to the interior is reduced in curved roofs. Curved roofs due to their form trap the heated air in the space under the roof and is ventilated through small windows in the clearstory [4]. As an advocate of regionalism and an opponent of the Le Corbusier's universalism-based designs, in 1941 Fathy designed the village of New Gourna that imbedded the architect's best intentions by using local materials, vaults and domes. However, mistakenly misreading the reluctance of the community to move to new site, New Gourna manifested for decades the inappropriateness of both programming and form. Appropriateness of architectural form to surrounding context, culture and landscape, remains an important question of how to create a culturally and environmentally valid architecture that is sensitive to regional traditions [5]. The Sharjah Central Souk was designed by Michael Lyle \& Partners in 1978, and it is part of an architectural trend in Sharjah in the 1970's and 80 s to create an identity for the city. The use of prefabricated concrete panels and the liberal use of ornament in the interior, together with the exterior tiles, produces a contemporary interpretation that is keeping with Arab/Islamic architectural forms and fragments [1]. The Museum of Islamic Civilization in Sharjah further cements the vocabulary of arches and domes used in the Gold bazaar to emphasize the production of modern heritage in Sharjah as part of constructing the identity of the city (figure $2 \&$ figure 3 ).

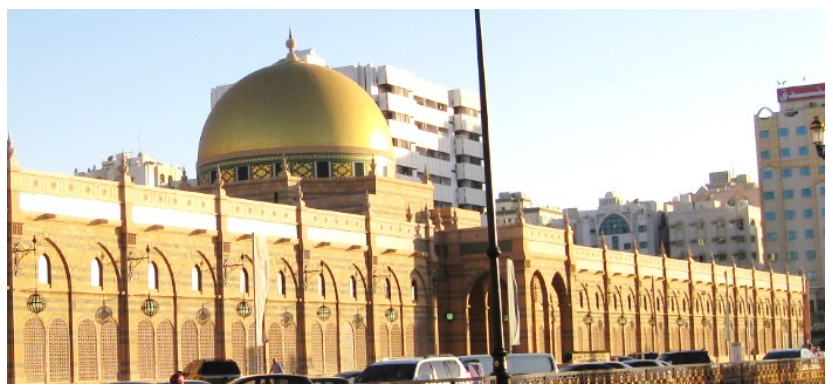

Fig. 2. Sharjah Islamic Museum

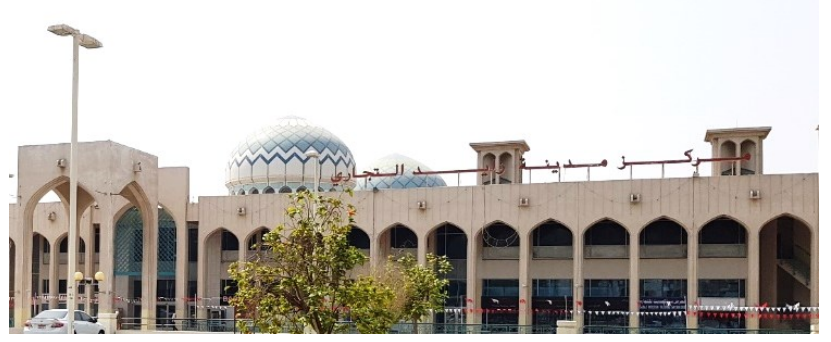

Fig. 3. Madinat Zayed Gold Souk- Abu Dhabi

\subsection{Modern Heritage in the UAE-the Gold Bazaar}

Environmental based design is part of the UAE heritage due to the harsh desert environment surrounding its cities. Colonnades and arcades have existed to allow for passive cooling of walls and are locally known as liwans, they were also meeting places and represent an important feature of local vernacular architecture because their shading effect, and integration between external landscape and buildings. Re-interpretation of the liwan as an architectural feature is best seen in Madinat Zayed Gold Souk in Abu Dhabi, coupled with domes and traditional wind-towers-barjeel, the Gold bazaar has a dual function as a commoditized space of gathering and exchange and an icon of the city's identity. In traditional cities the bazaar develops along a spatial structure that is linear and many of its shops are formed around the central axis. Such complexes are also conceived as secular spaces that are closely associated with mosques and public square [6]. Both gold bazaars in Sharjah and Abu Dhabi recruit solutions from regional precedents while keeping a critical distance to them. Arcades, domes and vaults are used to cover huge spaces of specialized production, which makes them popular 
especially in case of precious goods such as gold, textiles and carpets [7]. Historical examples such as the Grand bazaar in Istanbul operated based on a guild system which ensured that it functioned as both a cultural and economic entity, because on a socio-economic level, a bazaar acts as a space of inclusion to all. The grid created by the structural system, seen both in the modern bazaars and historical precedents are a product of the module of cross-vaults were used to offer standardized shop dimensions that could be enlarged based on multiplications of the module [8]. Therefore, the perception of the bazaar with its specialized shops all gathered under one roof, represent hybrid spaces within modern cities where different ethnic groups come into contact through everyday activity [9].

Madinat Zayed gold souk and the Gold Souk of Sharjah with their modular design, referencing to Islamic forms and ornament represent spaces of importance in the city as spaces of specialization of certain commodities, despite the emergence of Mega-Malls. They are also different in terms of design than contemporary shopping malls that manifest clear postmodern pastiches of eclectic ornament, in that they represent attempts of merging the modularity of the 'International Style' within the context of emerging modern Arab cities in the Gulf. The gold bazaars of the 1970's and 80's were part of modernist ideals to promote better integration of pedestrian use of space within the living city and they allowed social inclusion and urban assimilation through their design that included open spaces around them in downtown Abu Dhabi and Sharjah [10]. Today Modern Heritage and its contemporary interpretations can be understood within a psychological context as a form of an attempt to retain spaces of tradition through hybridization of local cultural material and modern design strategies within an era of rapid urban changes [11]. Regeneration of the downtown areas in aim to create a cohesive urban space offering a balanced land use that creates public spaces, supports social and cultural infrastructure to provide a catalyst better living through reinforcing city identity, and promote social inclusion [12]. The UAE's interest in sustainability as highlighted by the Estidama guidelines triggered urban renewal and cultural awareness in downtown areas, which instead of demolition can be redeveloped, rehabilitated and renovated to become an integral part of the collective memory of the city. Thereafter, the Gold bazaars of Abu Dhabi and Sharjah represent the cities modern heritage that needs to be sustained within a paradigm that involves different social, economic, and environmental dimensions related to the vitality of the city [13].

\section{Discussion and Recommendations}

Revisiting architectural heritage including modern spaces that re-employ traditional forms such as domes vaults and arcades as manifested by the Madinat Zayed Souk and Central Souk in Sharjah. Simulation of these facades helps us understand how considering shading leaves is affecting energy performance and sustainability (Figure 4).

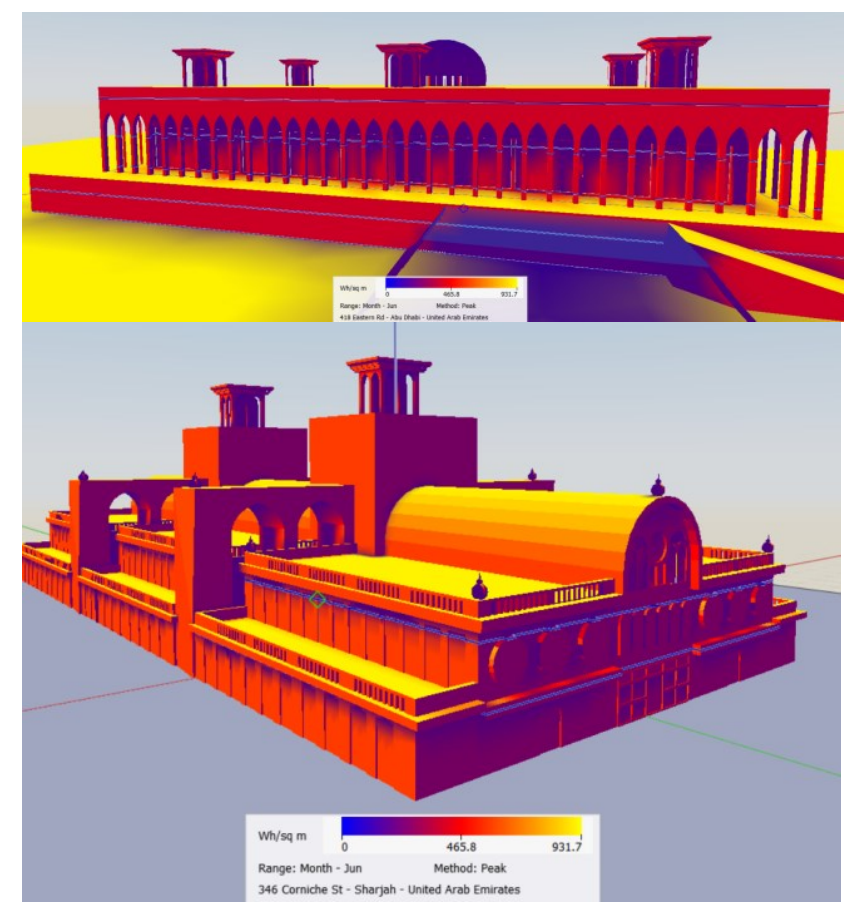

Fig. 4. Heat diagram in Madinat Zayed Souk and Central Souk in Sharjah

In these buildings they were considering that the primary function of the construction is to use the given elements to provide a shelter as a function of climate. The concept of the moderator was clearly used as a building envelope to control heat flow, air flow, and movement of water as vapor and as liquid, solar and other radiation. In the old stone Souq buildings they relied on the massive nature to withstand the weather conditions, unlike the modern buildings that has balloon like envelops that are comprised of thinner layers, that are individually less able to withstand the same elements and has even more critical performance .Since these buildings were constructed In hot dry (arid) climates, windows are clearly kept to a minimum to prevent the sun from entering the building. Bright stucco finishes are used to reflect light and keep the environment bright. As an aesthetic/sustainable improvement for the facades, we suggested adding dynamic Mashrabiya designed screen to add more shade and less heat transmission without affecting the cultural and traditional value of the building (figure 5). 


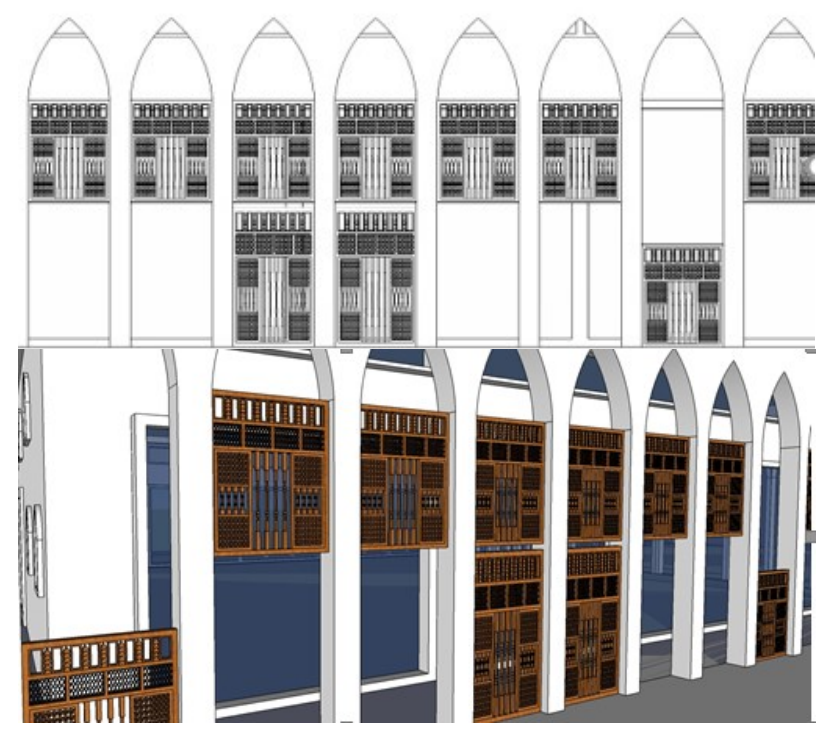

Fig. 5. Mashrabiya designed screens as a suggestion for thermal performance improvement.

An Approach to having a Passive Bio-climatic Design by reassessing the Comfort Zone in the surrounding area of the building was another suggestion for Sharjah central souk (figure 6), by creating pleasing and useful spaces outside of our buildings. Courtyards as a solution were applicable in such hot arid climates and works well because sun can warm these spaces in cooler months as well. The courtyard helps in enhancing the natural ventilation of the area and provides a shaded social space that betters adapts to the comfort zone of users and has improved thermal qualities - is cooler than the existing spaces exposed to direct sunlight.
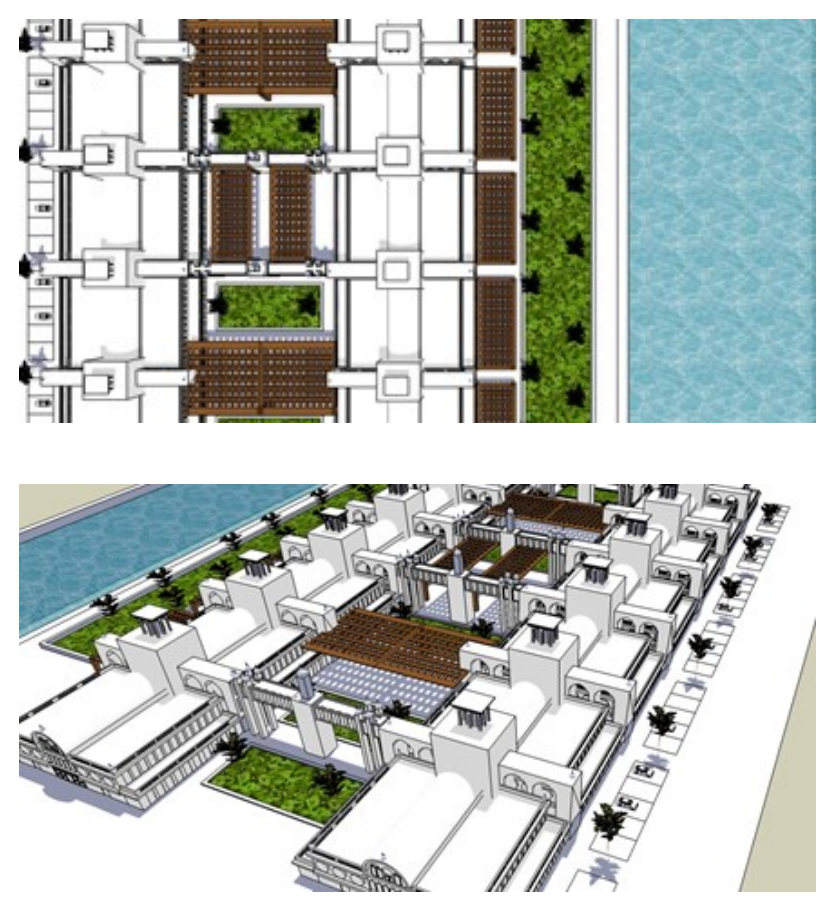

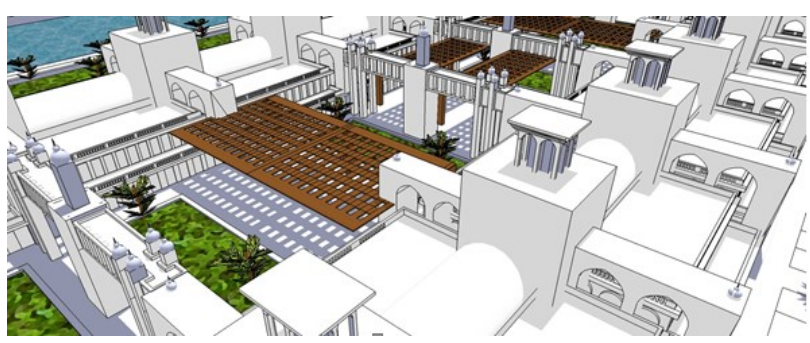

Fig. 6. The Passive Bio-climatic Design suggestion for Sharjah central souk

\section{Conclusion}

The bazaar has always played an important part of the living city, these covered spaces offer spaces of inclusion for different social and cultural activities in addition to specialized trading. Urban renewal is important to regenerate the gold bazaars of Sharjah and Abu Dhabi as part of the urban regeneration of the living city and downtown areas especially in light of the challenges created by Mega Malls that are much larger in scale and scope of activities. Collective memory and culture are part and parcel of the delicate realm of identity with a contrast between the old and the new as a model of productive resistance towards global homogenization. Modern heritage in the UAE attempted to use forms from the broader spectrum of Islamic art and architecture to create an identity for rapidly growing modern Arab cities. Today rapid changes are occurring in Gulf cities as they stride towards diversification of GDP and aim to attract residents and investors. Municipalities are challenged between heritage preservation versus modernization, especially that modern heritage is not as clear as historical heritage when it comes to local forms and building materials. This juxtaposition has generated parallel and contradictory attitudes towards modern heritage as part of the living city. However, because of the global interest for urban renewal of downtown areas in cities all over the world revival of the modern heritage of the UAE especially its Gold bazaars may become possible, with initiatives that aim at reutilization of space and social comfort. The domed and vaulted spaces of the Gold bazaars in Abu Dhabi and Sharjah reflect on how architects attempted to apply the functionality of the International style and create shading screens and patterns abstracted from historical references.

\section{References}

1. N. Othman Ahmad, N. Urbanism and Town Planning, Observations on the development of Abu Dhabi, ed. Damluji, The Architecture of the United Arab Emirates, Garnet Publishing (2006)

2. P. Menoret, Introduction to The Abu Dhabi Guide: Modern Architecture, in P. Menoret (ed.) The Abu Dhabi Guide, Modern Architecture 1950-1990's, (2014) 
3. M. Hadavand \& Yaghoubi, Thermal Behaviour of Curved Roof Buildings Exposed to Solar Radiation And Wind Flow For Various Orientations, Applied Energy 85, 663-679 (2008)

4. R. Tang, I.A Meir, T. Wu, Thermal Performance Of Non Air-Conditioned Buildings With Vaulted Roofs In Comparison With Flat Roofs. Building and Environment 41,268-276 (2006)

5. Steele, J. The Hassan Fathy Collection. Geneva, Switzerland: Aga Khan Trust for Culture (1989)

6. Pourjafara, M., Amini M., Hatami, E.V., Mahdavinejad, M. Role of bazaars as a unifying factor in traditional cities of Iran: The Isfahan bazaar, Frontiers of Architectural Research 3,1 1019 (2014)

7. Karimi, Moradi, E. Mehri, T. Bazaar, As a Symbol of Culture and the Architecture of Commercial Spaces in Iranian-Islamic Civilization. Cumhuriyet University Faculty of Science Journal (CSJ), 36,6(2015).

8. Wohl, S. The Grand Bazaar in Istanbul: The Emergent Unfolding of a Complex Adaptive System. International Journal of Islamic Architecture,4,1 39-73(2015)

9. Duruz, A. Luckman, S. and Bishop. P.Bazaar encounters: Food, markets, belonging and citizenship in the cosmopolitan city. Journal of Media \& Cultural Studies. 25,5 599-604 (2011)

10. Viola, Serena. Urban Renewal and Sustainable Development Efforts in Montreal: Vitality and Multiculturalism Requirements from an Identity Protection Perspective, International Journal of Canadian Studies /Revue internationale d'études canadiennes, 37(2008)

11. King, D.A. Spaces of global cultures: architecture, urbanism, identity, New York: Routledge (2004)

12. Khalil. R. Shaaban, K. Rebuilding Old Downtowns: the Case of Doha, Qatar, Proceedings REAL CORP 2012 Tagungsband 14-16 (2012)

13. Tang, H. and Lee, Y.M. The Making of Sustainable Urban Development: A Synthesis Framework, Sustainability, 8, 492 1-28. (2016) 